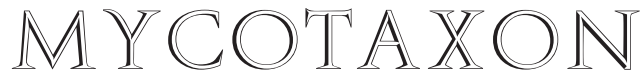

Volume 123, pp. 419-429

http://dx.doi.org/10.5248/123.419

January-March 2013

\title{
Studies of two Corner types (Marasmius nigroimplicatus and $M$. subrigidichorda) and new Gymnopus combinations
}

\author{
Zdenko TkalČec \& Armin Mešić* \\ Ruđer Bošković Institute, Bijenička cesta 54, HR-10000 Zagreb, Croatia \\ *CORRESPONDENCE TO: ztkalcec@irb.hr\&*amesic@irb.hr
}

Aвstract - Type specimens of Marasmius nigroimplicatus and M. subrigidichorda were studied. Based on morphological studies, both species belong to Gymnopus, sect. Androsacei. Color photographs of dried basidiomata and microscopic characters accompany the detailed descriptions. New combinations are proposed for these two taxa. Nine related marasmioid species are transferred to Gymnopus.

Key words - Agaricales, Basidiomycota, Omphalotaceae, taxonomy

\section{Introduction}

Corner (1996) described 99 new white-spored agaric species from Malesian region, of which 87 were placed in the genus Marasmius. However, he used a very broad generic concept of Marasmius that includes several genera (Gloiocephala, Gymnopus, Marasmiellus, Rhodocollybia, etc.) which have mostly been accepted as good genera and whose concepts have also been supported by phylogenetic analyses (e.g., Wilson \& Desjardin 2005, Tan et al. 2009, Antonín \& Noordeloos 2010). Consequently, most of the Marasmius species described by Corner (1996) should be transferred into the new genera.

During the process of describing the new species, Gymnopus fuscotramus Mešić et al. (Mešić et al. 2011), we studied types of two similar species described by Corner (1996), Marasmius nigroimplicatus and M. subrigidichorda, known only from their type localities in Singapore. In this paper we give detailed species descriptions, as well as color photographs of their dried basidiomata and microscopic characters. The two species are characterized by small marasmioid basidiomata, thin insititious dark colored stipes, well-developed black rhizomorphs, dextrinoid trama of stipe, and non-hymeniform pileipellis. According to these characters, neither species belongs to Marasmius in the modern sense, but to Gymnopus, sect. Androsacei (Kühner) Antonín \& Noordel. 
(Wilson \& Desjardin 2005, Noordeloos \& Antonín 2008, Antonín \& Noordeloos 2010). Therefore, we propose new combinations in Gymnopus (Pers.) Roussel for the two studied species, as well as for nine related marasmioid species in sect. Androsacei based on their morphological characters.

\section{Materials \& methods}

The descriptions of Gymnopus nigroimplicatus and G. subrigidichorda are completely based on the type collections deposited at the Royal Botanic Garden Edinburgh (E). The following abbreviations are used in macroscopic description: L for number of lamellae and 1 for number of lamellulae between two lamellae. Microscopic features were observed with a light microscope (brightfield and phase contrast $(\mathrm{PhC})$ ) under magnification up to $1500 \times$ and photographed with a digital camera. Descriptions and images of microscopic characters were made from rehydrated dried specimens mounted in $2.5 \%$ potassium hydroxide $(\mathrm{KOH})$ solution. Amyloidity and dextrinoidity were tested in Melzer's reagent (Erb \& Matheis 1983). Basidiospore measurements were made from mounts of lamellae and based on calibrated digital images. For G. nigroimplicatus, three mature basidiomata were chosen and 20 basidiospores were measured in total (spores were scarce), while for G. subrigidichorda, two mature basidiomata were chosen and 50 randomly selected basidiospores were measured in total. Spore measurements (length, width) include apiculus and are given as: (min.) stat. min. - av. - stat. max. (max), where "min." = minimum (lowest measured value), "stat. min." = statistical minimum (arithmetic average minus $2 \times$ standard deviation), "av." = arithmetic average, "stat. max." = statistical maximum (arithmetic average plus $2 \times$ standard deviation), "max." = maximum (highest measured value). Standard deviation (SD) of spore length and width is also given. The length/width ratio of spores is given as the "Q" value (min. - av. - max.). Comparison of G. nigroimplicatus and G. subrigidichorda with similar species is based on descriptions and illustrations in the following literature: Petch 1948, Singer 1965, 1969, 1976, 1989, Pegler 1986, Desjardin 1987, Corner 1996, Antonín 2007, Mešić et al. 2011.

\section{Taxonomy}

Type studies

Gymnopus nigroimplicatus (Corner) Mešić \& Tkalčec, comb. nov. Plates 1, 3-7 MrcoBAnk MB 564875

$\equiv$ Marasmius nigroimplicatus Corner, Beih. Nova Hedwigia 111: 75. 1996. Type: SINGAPORE: Botanic Garden, 14 Aug 1940, leg. E. J. H. Corner, (E 206719, holotype).

The following description is compiled from the dried holotype collection, which consists of approximately 12 basidiomata, partially fragmented or badly preserved, accompanied with abundant rhizomorphs. Basidiomata and rhizomorphs arising from dead leaves. Basidiomata are not connected with rhizomorphs. Pileus 3-8.5 mm broad, convex or conico-convex at first, later applanate, slightly striate-sulcate, matt, homogeneous brown. LAMELLAE 

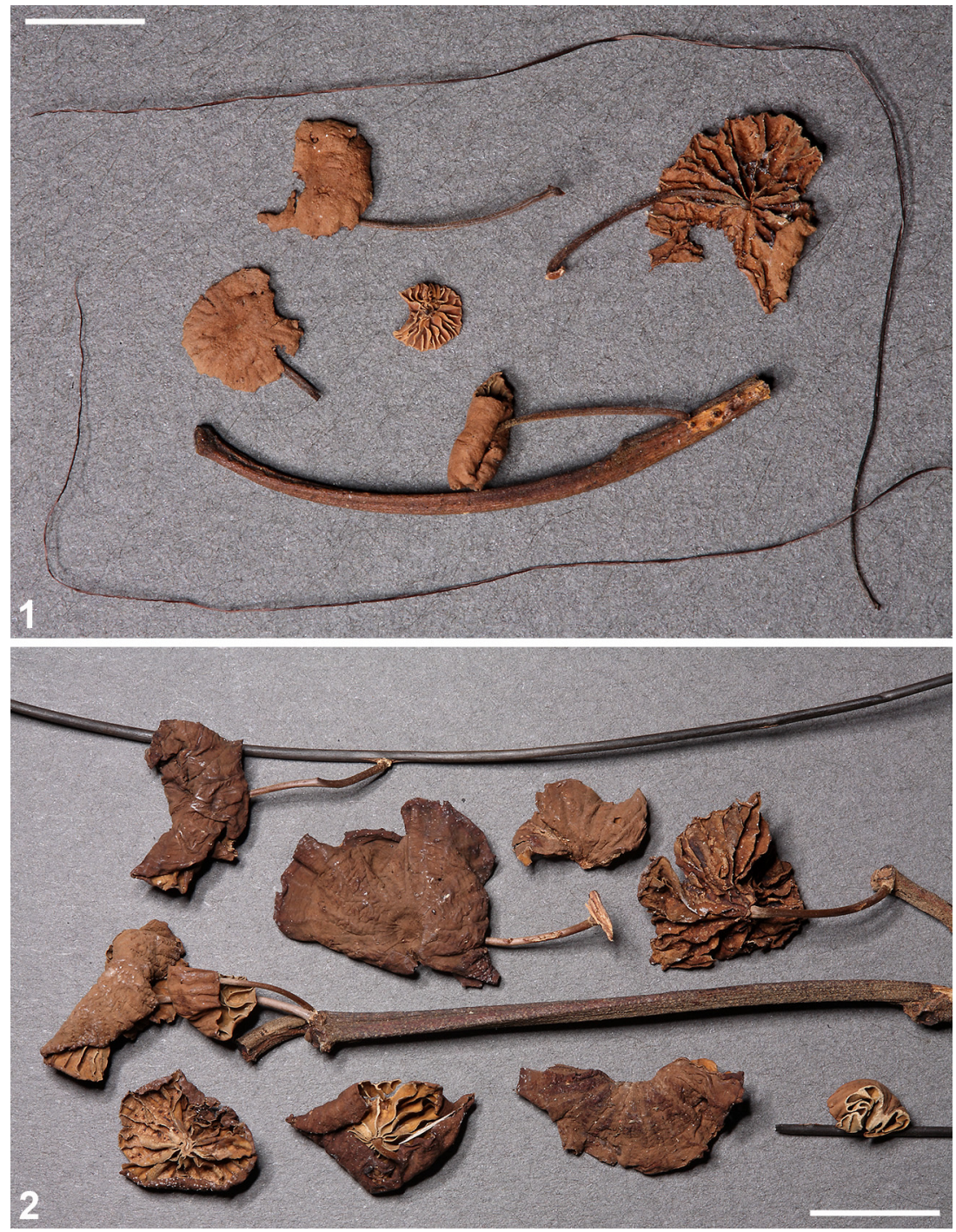

Plates 1-2. Dried basidiomata (holotypes).

1. Marasmius nigroimplicatus. 2. Marasmius subrigidichorda. Bars: $1=5 \mathrm{~mm} ; 2=10 \mathrm{~mm}$.

adnate or attached to a pseudocollarium, distant, $\mathrm{L}=10-14,1=1-3, \leq 1 \mathrm{~mm}$ broad, sometimes furcate, brown (concolorous with pileus), with an entire, concolorous edge. STIPE 7-23 × 0.15-0.40 mm, subcylindrical, dark brown, surface densely minutely dark brown pubescent, insititious. ConTExt brown. 
RHIZOMORPHS filiform, mostly gradually tapering towards the apex, $\leq 70 \mathrm{~mm}$ long, $0.05-0.20 \mathrm{~mm}$ thick near the base, rarely branched, mostly minutely pubescent (especially in the lower half), dark brown to black.

BASIDIOSPORES [20/3/1] (7.1-)6.8-8.7-10.5(-11.0) × (2.3-)2.3-3.0-3.7 $(-3.6) \mu \mathrm{m}, \mathrm{SD}=0.93 \times 0.36, \mathrm{Q}=2.35-2.95-3.87$, cylindrical to bacilliform, mostly with conical base and rounded apex in frontal view, (sub)amygdaliform or lacrymoid in side view, smooth, hyaline, thin-walled, non-amyloid, nondextrinoid. BASIDIA 20-25 × 6.5-7 $\mu \mathrm{m}$, clavate, 4-spored, thin-walled, pale brownish to pale brown, light brown in mass. BAsidioles mostly fusoid, but also subcylindrical, narrowly utriform or narrowly clavate, often mucronate to rostrate (and then sometimes with subcapitate apex). LAMELLAR EDGE sterile. Cheilocystidia abundant, 21-50 × 8-27 $\mu \mathrm{m}$, coralloid, with clavate to irregularly shaped body $(10-30 \times 3-9 \mu \mathrm{m})$ and mostly abundant, strongly branched projections, thin-walled, hyaline to pale yellowish brown. Pleurocystidia absent. Hymenophoral trama rather irregular, composed of pale brownish to pale brown (light brown in mass), often branched, 1-6 $\mu \mathrm{m}$ broad, thin-walled hyphae. PiLEIPELlis an irregular cutis, hyphae 2-10 $\mu \mathrm{m}$ broad, thin-walled, smooth to diverticulate, terminal elements sometimes subcoralloid, subhyaline to brown, pigment often minutely to coarsely encrusted. STIPITIPELLIS a cutis of parallel, cylindrical, $3-10 \mu \mathrm{m}$ broad, browngray hyphae with encrusted pigment. CAulocystidia abundant, formed as lateral or terminal elevations of stipitipellis cells, 5-93 $\times 4-12 \mu \mathrm{m}$, cylindrical, subcylindrical, less frequently somewhat flexuose, rarely branched, always with obtuse apex, thick-walled (1.8-5 $\mu \mathrm{m}$ thick), brown-gray, pigment parietal. STIPE TRAMA composed of (sub-)hyaline, parallel, thin- to thick-walled ( $\leq 4 \mu \mathrm{m}$ thick), 2-9 $\mu$ m broad hyphae. CLAMP CONNECTIONs present in all tissues.

Chemical Reactions - All parts of basidioma non-amyloid and nondextrinoid except hyphae in cortical layer of stipe and caulocystidia, which are strongly dextrinoid.

НАвітAт - On dead leaves in botanic garden.

Distribution - Known only from the type locality in Singapore, Asia.

REMARKs - Gymnopus nigroimplicatus is characterized by purplish brown to cinnamon brown colors in pileus, lamellae, and stipe; slightly striate-sulcate pileus; lamellae adnate or attached to a pseudocollarium; an insititious, dark brown, and minutely pubescent stipe; well-developed black rhizomorphs; basidiomata growing only on dead leaves (not arising from rhizomorphs); nonhymeniform pileipellis (irregular cutis); subcylindrical, cylindrical or lacrymoid spores; presence of clamp connections in all tissues; coralloid cheilocystidia; abundant thick-walled caulocystidia with obtuse apex; and dextrinoid hyphae in cortex of stipe. We consider it a good species. 

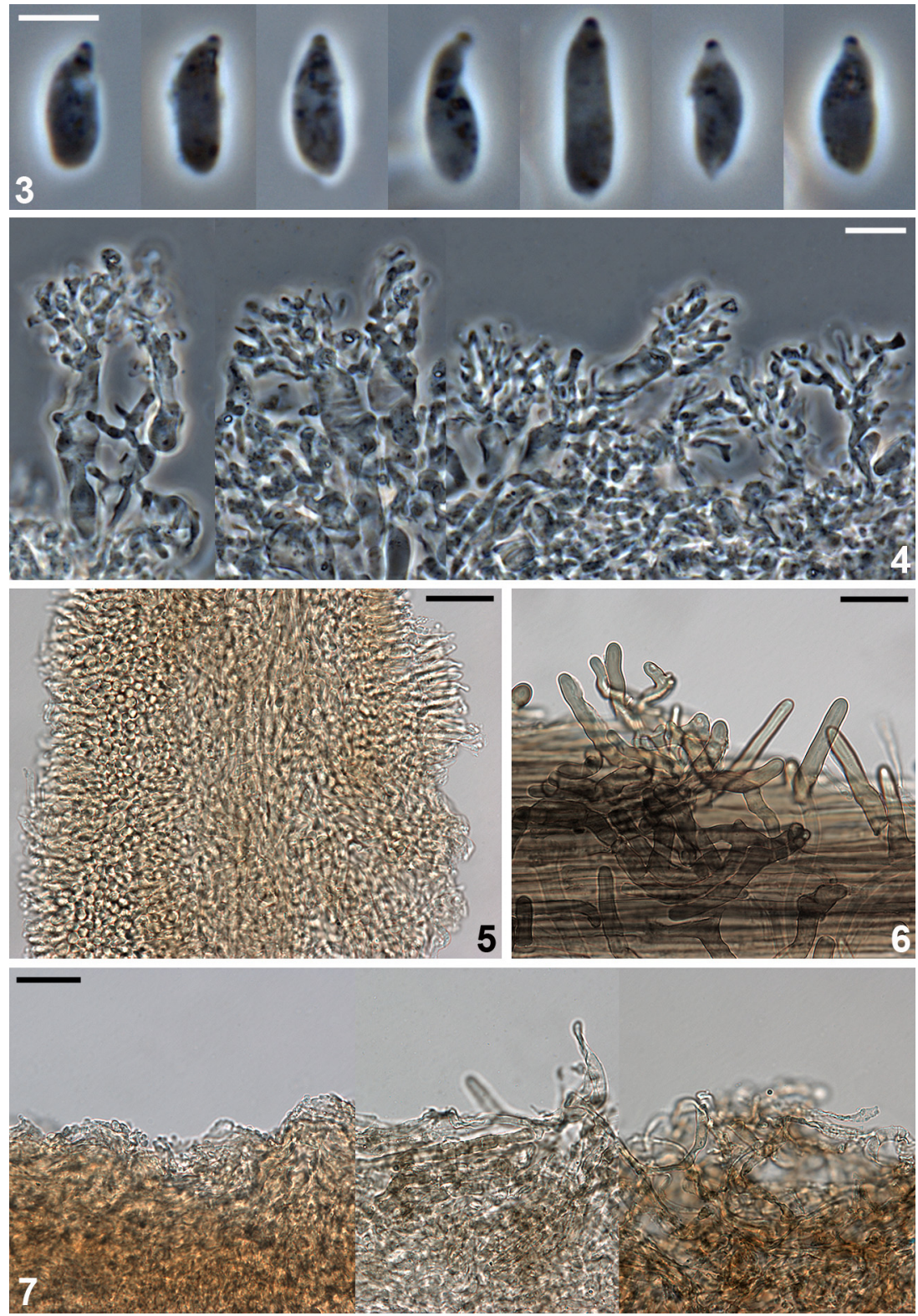

Plates 3-7. Marasmius nigroimplicatus. 3. Spores (PhC). 4. Cheilocystidia (PhC). 5. Hymenophoral trama. 6. Caulocystidia. 7. Pileipellis. Bars: $3=5 \mu \mathrm{m} ; 4=10 \mu \mathrm{m} ; 5-7=30 \mu \mathrm{m}$. 
Among other species in sect. Androsacei with clamp connections, black rhizomorphs, non-glabrous stipe, and colored (not white or cream) pileus and lamellae, G. bactrosporus has a smaller pileus (2.5-3.5 $\mathrm{mm}$ broad), whitish to light sordid gray lamellae, longer spores $(10-12 \times 2.7-3.7 \mu \mathrm{m})$, well-developed pleurocystidia, and different cheilocystidia. Gymnopus brevistipitatus has a smaller pileus (2-4 $\mathrm{mm}$ broad), shorter stipe (2-3 $\mathrm{mm}$ long), fewer lamellae ( $\mathrm{L}=7-9)$, and smaller caulocystidia $(20-40 \mu \mathrm{m}$ long) with apical projections or coralloid. Gymnopus campinaranae has a smaller pileus (2-3 $\mathrm{mm}$ broad), thinner stipe $(\leq 0.1 \mathrm{~mm}$ wide), and larger spores $(9-13 \times 3.2-4.5 \mu \mathrm{m})$. Gymnopus fuscotramus has free lamellae, glabrous and thicker rhizomorphs ( $\leq 0.5 \mathrm{~mm}$ wide), less elongated spores, and caulocystidia with thinner walls [0.5-2(-2.5) $\mu \mathrm{m}$ thick]. Gymnopus rhizomorphicola has a shorter $( \pm 3 \mathrm{~mm}$ long) eccentric curved stipe, fewer lamellae $(\mathrm{L}=7-8)$, and basidiomata arising from rhizomorphs. Gymnopus rigidichorda has mature creamy white lamellae, thicker (0.4-0.6 mm wide) glabrous rhizomorphs, and differently shaped noncoralloid cheilocystidia. Gymnopus subrigidichorda has an umbilicate pileus, broader lamellae, longer and thicker rhizomorphs, broader spores $(4-5 \mu \mathrm{m}$ wide), and rare clamp connections (seen only in stipe trama). Gymnopus thiersii has rare or absent rhizomorphs, crowded lamellae, and lacks cheilocystidia.

Gymnopus subrigidichorda (Corner) Tkalčec \& Mešić, comb. nov. Plates 2, 8-12

MycoBank MB 564876

$\equiv$ Marasmius subrigidichorda Corner, Beih. Nova Hedwigia 111: 99, 1996. Type:

SINGAPORE: Bukit Timah, 11 Nov 1929, leg. E. J. H. Corner, (E 206861, holotype).

The following description is compiled from the dried holotype collection, which consists of 20 basidiomata in good condition accompanied with abundant rhizomorphs. Basidiomata arising from 2-8 mm wide twigs as well as from rhizomorphs. PILEus $6.5-19 \mathrm{~mm}$ broad, convex to plano-convex with an umbilicate center, sometimes with a small papilla in the central depression, striate-sulcate up to the center, matt, homogeneous brown to dark brown. LAMELLAE attached to a pseudocollarium, distant, $\mathrm{L}=12-14, \mathrm{l}=1-3, \leq 2.5 \mathrm{~mm}$ broad, often intervenose, yellowish brown to brown, with an entire, concolorous edge. STIPE 4-17 $\times 0.6-0.9 \mathrm{~mm}$, subcylindrical (slightly broadened at the base and the apex), brown to dark brown, surface moderately to densely minutely brown pubescent (under a hand-lens), sub-insititious with small pale brown fibrils at the base. CONTEXT pale brown. RHIzOMORPHS robust, $\leq 410 \mathrm{~mm}$ long and $\leq 0.9 \mathrm{~mm}$ thick, occasionally branched, glabrous, shiny, stiff, black with a pale brown apex, medulla pale brown.

BASIDIOSPORES [50/2/1] (6.2-)6.4-8.3-10.2(-10.2) × (4.0-)4.0-4.5-5.1 $(-5.1) \mu \mathrm{m}, \mathrm{SD}=0.95 \times 0.27, \mathrm{Q}=1.43-1.82-2.18$, ellipsoid to elongate (sometimes cylindrical), mostly with conical base and rounded apex in frontal view, mostly 

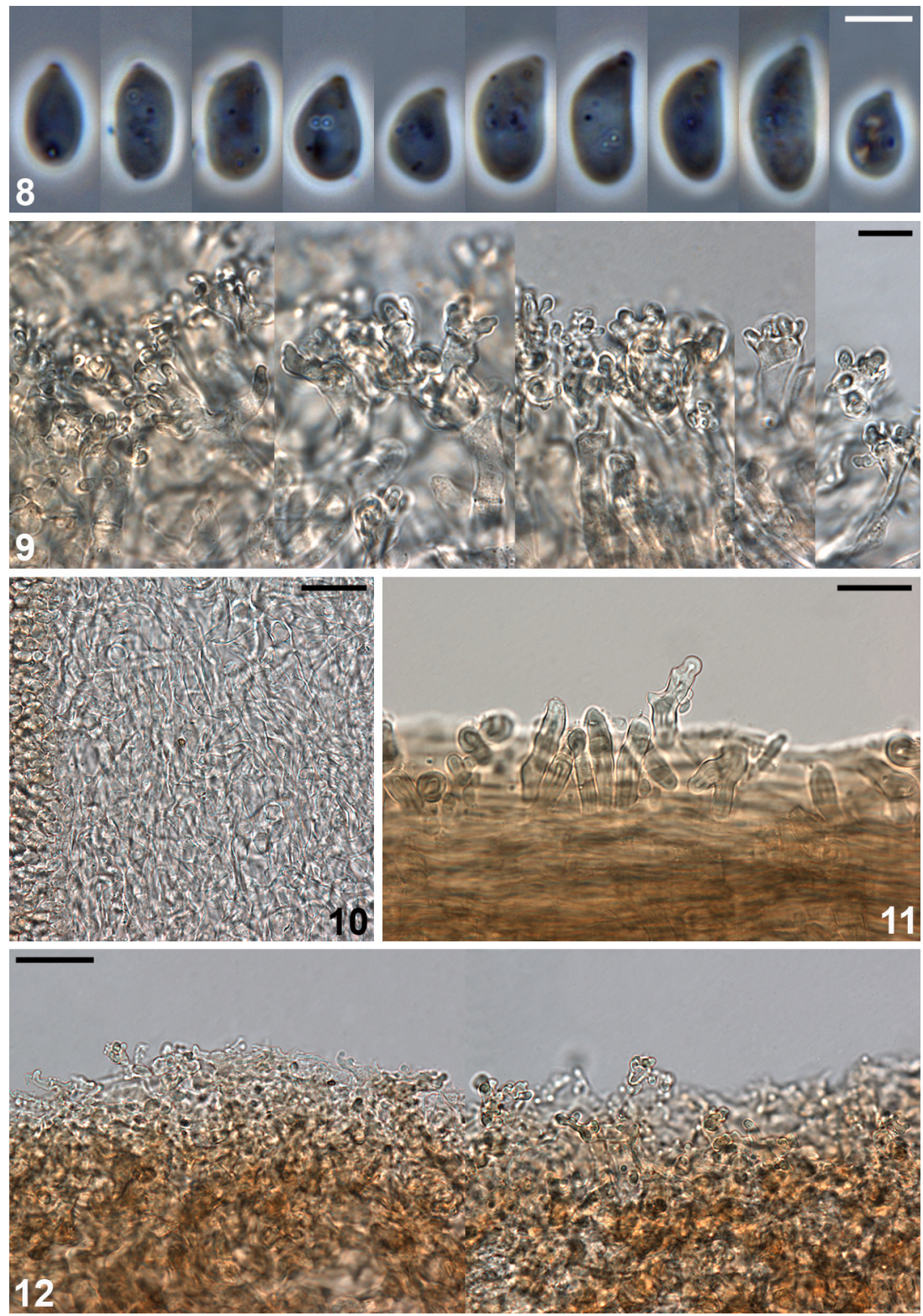

Plates 8-12. Marasmius subrigidichorda. 8. Spores (PhC). 9. Cheilocystidia. 10. Hymenophoral trama. 11. Caulocystidia. 12. Pileipellis. Bars: $8=5 \mu \mathrm{m} ; 9=10 \mu \mathrm{m} ; 10-12=30 \mu \mathrm{m}$. 
(sub)amygdaliform or lacrymoid in side view, smooth, hyaline, thin-walled, non-amyloid, non-dextrinoid. BASIDIA 26-38 × 6.5-10 $\mu \mathrm{m}$, clavate, 4-spored, thin-walled, subhyaline to pale brown, light brown in mass, pigment intracellular and granular. BASIDIOLES narrowly clavate, cylindrical or fusoid, sometimes mucronate to rostrate. LAmellar EDGE heterogeneous. Cheilocystidia scattered to locally abundant, $13-32 \times 7.5-20 \mu \mathrm{m}, \pm$ clavate with irregular apical projections of different types (nodose, digitate or branched), thin-walled, subhyaline to pale brown in KOH. Pleurocystidia absent. Hymenophoral TRAMA irregular, composed of hyaline, sometimes slightly gelatinized, often branched hyphae, 3-14 $\mu \mathrm{m}$ broad, thin- to moderately thick-walled $(\leq 0.8 \mu \mathrm{m}$ thick). PILEIPELLIS an irregular cutis of mostly nodose to diverticulate \pm repent hyphae (3-10 $\mu \mathrm{m}$ broad) and abundant \pm erect, lobed to irregularly coralloid terminal elements, projections knob-like, digitate or clavate, $2-10(-20) \times 2-5$ (-9) $\mu \mathrm{m}$, hyphae thin-walled, subhyaline to light brown in KOH. PILEus trama composed of hyaline, interwoven, partly gelatinized, thin- to moderately thickwalled ( $\leq 1 \mu \mathrm{m}$ thick), 1.5-11 $\mu \mathrm{m}$ broad hyphae. STIPITIPELLIS a cutis of parallel, cylindrical, $\leq 13 \mu \mathrm{m}$ broad, thick-walled hyphae ( $\leq 6 \mu \mathrm{m}$ thick), mostly brown in $\mathrm{KOH}$, pigment parietal. CAULOCYSTIDIA abundant in upper part of stipe, $18-50(60) \times 7-12 \mu \mathrm{m}$, subcylindrical to narrowly clavate with an obtuse apex, sometimes branched, thick-walled ( $2-5 \mu \mathrm{m}$ thick), subhyaline to light brown in $\mathrm{KOH}$. STIPE TRAma composed of (sub)hyaline, parallel, thin- to thick-walled ( $\leq 4 \mu \mathrm{m}$ thick), $2-8 \mu \mathrm{m}$ broad hyphae. ClAmp CONNECTIONs rare, seen only in stipe trama.

Chemical ReACtions - all parts of basidioma non-amyloid and nondextrinoid except hyphae in cortical layer of stipe and caulocystidia, which are strongly dextrinoid.

НАвIтAT - In forest, on dead twigs.

Distribution - Known only from the type locality in Singapore, Asia.

REMARKs - Gymnopus subrigidichorda is characterized by a rufous brown striate-sulcate pileus with umbilicate center; incarnate to rufous brown lamellae attached to the pseudocollarium; sub-insititious minutely pubescent, brown stipe; abundant robust black rhizomorphs; basidiomata both growing on twigs and arising from rhizomorphs; non-hymeniform pileipellis (irregular cutis with lobed to coralloid terminal elements); ellipsoid, oblong, or lacrymoid spores; rare clamp connections (present only in stipe trama); clavate cheilocystidia with irregular apical projections; abundant thick-walled caulocystidia with obtuse apex; and dextrinoid hyphae in the stipe cortex. We consider it a good species. Our description pretty well agrees with the original description, except in spore size, which is significantly smaller $(4.5-6.0 \times 3.5-4.0 \mu \mathrm{m})$ in original description (Corner 1996). 
Among other species in sect. Androsacei with clamp connections, black rhizomorphs, non-glabrous stipe, and colored (not white or cream) pileus and lamellae, G. bactrosporus has a smaller pileus (2.5-3.5 mm broad), hyalinepilose stipe (under a hand-lens), longer $(10-12 \times 2.7-3.7 \mu \mathrm{m})$ and more elongated spores, well-developed pleurocystidia, and thin-walled caulocystidia. Gymnopus brevistipitatus has a smaller pileus (2-4 mm broad), shorter stipe (2-3 mm long), fewer lamellae ( $\mathrm{L}=7-9)$, and more elongated, narrower spores (2.5-3.7 $\mu \mathrm{m}$ wide). Gymnopus campinaranae has a smaller pileus $(2-3 \mathrm{~mm}$ broad), thinner stipe ( $\leq 0.1 \mathrm{~mm}$ wide), and larger spores $(9-13 \times 3.2-4.5 \mu \mathrm{m})$. Gymnopus fuscotramus has free lamellae, shorter ( $\leq 135 \mathrm{~mm}$ long) and thinner rhizomorphs ( $\leq 0.5 \mathrm{~mm}$ wide), more elongated spores, gray-brown pileal and hymenophoral trama, and caulocystidia with thinner walls $(0.5-2(-2.5) \mu \mathrm{m}$ thick). Gymnopus nigroimplicatus has a pileus without central depression, narrower lamellae, shorter and thinner rhizomorphs, narrower spores (2.3-3.7 $\mu \mathrm{m}$ wide) and clamp connections present in all tissues (not only in stipe trama). Gymnopus rhizomorphicola has a shorter ( $\pm 3 \mathrm{~mm}$ long), eccentric and curved stipe, fewer lamellae $(\mathrm{L}=7-8)$, more elongated spores $(\mathrm{Q}=2.1-2.9)$, and larger caulocystidia $(45-190 \times 6-26 \mu \mathrm{m})$. Gymnopus rigidichorda has creamy white mature lamellae and very narrow thinner $(0.4-0.6 \mathrm{~mm}$ wide) rhizomorphs, differently shaped non-coralloid cheilocystidia, and narrower spores (3-3.5 $\mu \mathrm{m}$ wide). Gymnopus thiersii has rare or absent rhizomorphs, crowded lamellae, and lacks cheilocystidia. Because G. subrigidichorda has rare clamp connections (seen only in stipe trama) it could also be confused with a few species that lack clamp connections. Gymnopus aporpohyphes differs by a smaller ( $\leq 5 \mathrm{~mm}$ broad) and convex pileus with small umbo, whitish to pale avellaneous lamellae, narrower cheilocystidia (4-6.5 $\mu \mathrm{m}$ wide), and more elongated narrower $(2.8-3.2 \mu \mathrm{m}$ wide) spores. Gymnopus pacificus differs by a smaller pileus (5-6.5 $\mathrm{mm}$ broad), narrower stipe (0.2-0.3 mm wide), narrower spores $(3.5-4.1 \mu \mathrm{m}$ wide), and caulocystidia with thinner walls $(0.5-1.5 \mu \mathrm{m}$ wide). Gymnopus tomentellus differs by a smaller pileus (1-3 $\mathrm{mm}$ broad) without a central depression, smaller stipe $(1-4 \times 0.2-0.6 \mathrm{~mm})$, larger and more elongated spores $(11-11.5 \times 4-5 \mu \mathrm{m})$, and caulocystidia with thinner walls (ca. $1 \mu \mathrm{m}$ wide).

\section{Additional new combinations in Gymnopus}

Gymnopus aporpohyphes (Singer) Tkalčec \& Mešić, comb. nov.

MycoBank MB 800668

= Marasmius aporpohyphes Singer, Sydowia 18: 333, 1965 [“1964”].

Gymnopus bactrosporus (Singer) Mešić \& Tkalčec, comb. nov.

MycoBank MB 800669

” Marasmius bactrosporus Singer, Sydowia 18: 334, 1965 [“1964”]. 
Gymnopus brevistipitatus (Antonín) Tkalčec \& Mešić, comb. nov.

MycoBAnk MB 800670

三Setulipes brevistipitatus Antonín, Mycotaxon 88: 71, 2003.

Gymnopus campinaranae (Singer) Mešić \& Tkalčec, comb. nov.

MycoBank MB 800671

= Marasmius campinaranae Singer, Fieldiana, Bot. 21: 57, 1989.

Gymnopus pacificus (Singer) Tkalčec \& Mešić, comb. nov.

MycoBank MB 800672

$\equiv$ Marasmius pacificus Singer, Beih. Nova Hedwigia 29: 95, 1969.

Gymnopus rhizomorphicola (Antonín) Mešić \& Tkalčec, comb. nov.

MycoBAnk MB 800673

三Setulipes rhizomorphicola Antonín, Mycotaxon 88: 75, 2003.

Gymnopus rigidichorda (Petch) Tkalčec \& Mešić, comb. nov.

MycoBank MB 800674

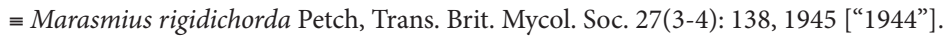

Gymnopus thiersii (Desjardin) Mešić \& Tkalčec, comb. nov.

MycoBank MB 800675

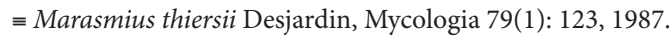

Gymnopus tomentellus (Berk. \& M.A. Curtis) Tkalčec \& Mešić, comb. nov.

MrcoBank MB 800676

$\equiv$ Marasmius tomentellus Berk. \& M.A. Curtis, J. Linn.

Soc., Bot. 10(45): 298, 1868 [“1869”].

\section{Acknowledgments}

We are grateful to the Royal Botanic Garden Edinburgh (E) for the loan of Corner's holotype collections. We would also like to thank Vladimír Antonín (Brno, Czech Republic) and Clark L. Ovrebo (Edmond, OK, USA) for their critical reviews of the manuscript.

\section{Literature cited}

Antonín V. 2007. Monograph of Marasmius, Gloiocephala, Palaeocephala and Setulipes in tropical Africa. Fungus flora of tropical Africa 1. National Botanic Garden: Meise (Belgium).

Antonín V, Noordeloos ME. 2010. A monograph of marasmioid and collybioid fungi in Europe. IHW-Verlag: Eching (Germany).

Corner EJH. 1996. The agaric genera Marasmius, Chaetocalathus, Crinipellis, Heimiomyces, Resupinatus, Xerula and Xerulina in Malesia. Beih. Nova Hedwig. 111: 1-175.

Desjardin DE. 1987. New and noteworthy marasmioid fungi from California. Mycologia 79(1): 123-134. http://dx.doi.org/10.2307/3807751

Erb B, Matheis W. 1983. Pilzmikroskopie. Kosmos: Stuttgart (Germany).

Mešić A, Tkalčec Z, Deng C-Y, Li T-H, Pleše B, Ćetković H. 2011. Gymnopus fuscotramus (Agaricales), a new species from southern China. Mycotaxon 117: 321-330.

http://dx.doi.org/10.5248/117.321 
Noordeloos ME, Antonín V. 2008. Contribution to a monograph of marasmioid and collybioid fungi in Europe. Czech Mycol. 60(1): 21-27.

Pegler DN. 1986. Agaric flora of Sri Lanka. Kew Bulletin Additional Series 12. HMSO, London.

Petch T. 1948. A revision of Ceylon Marasmii. Trans. Brit. Mycol. Soc. 18(2): 19-44 + pl. II-IV.

Singer R. 1965 [“1964"]. Monographic studies on South American Basidiomycetes, especially those of the East Slope of the Andes and Brazil. 2.) The genus Marasmius in South America. Sydowia 18: 106-358.

Singer R. 1969. Mycoflora australis. Beih. Nova Hedwigia 29. J. Cramer, Lehre.

Singer R. 1976. Marasmieae (Basidiomycetes - Tricholomataceae). Flora Neotropica 17. The New York Botanical Garden, New York.

Singer R. 1989. New taxa and new combinations of Agaricales (Diagnoses fungorum novorum agaricalium IV). Fieldiana, Bot. 21: 1-133.

Tan Y-S, Desjardin DE, Perry BA, Vikineswary S, Noorlidah A. 2009. Marasmius sensu stricto in Peninsular Malaysia. Fungal Diversity 37: 9-100.

Wilson AW, Desjardin DE. 2005. Phylogenetic relationships in the gymnopoid and marasmioid fungi (Basidiomycetes, euagarics clade). Mycologia 97(3): 667-679.

http://dx.doi.org/10.3852/mycologia.97.3.667 